International Journal of Health Sciences
Available online at http://sciencescholar.us/journal/index.php/ijhs
Vol. 3 No. 3, December 2019, pages: $17 \sim 24$
e-ISSN: 2550-696X, p-ISSN: $2550-6978$
https://doi.org/10.29332/ijhs.v3n3.345

\title{
Critical Assessment of Paradigms in the Study of Decision Making on Sport
}

\author{
Amaya Castillo Caurel a , José Ignacio Ruiz Sánchez b \\ Article history: Received 27 May 2019, Accepted: 31 August 2019, Published: 15 October 2019
}

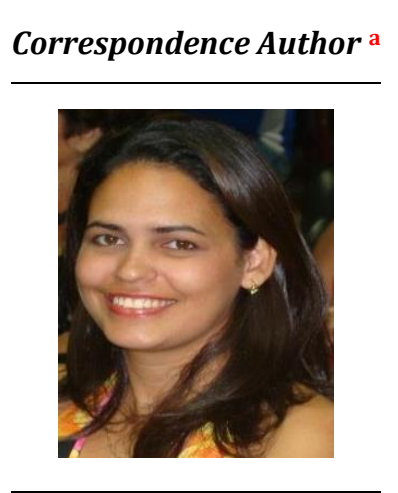

Keywords

cognitive paradigm; critical assessment; decision making; ecological paradigm; sport;

\begin{abstract}
In this critical assessment of the decision-making process in sport some ideas are clarified around an issue addressed in recent times. To this end, different perspectives are addressed: cognitive paradigm and ecological paradigm with the intention of referring, from a critical point of view, both to their convergences and to their theoretical divergences. A critical assessment is made on their object of study, the theories on which they are based, as well as the fundamental indicators and concepts they handle, based on the study conducted by García, Araujo, Carvalho \& Del Villar (2011). Bear in mind that both constitute ways of understanding and explaining the decision process to improve sports performance. Finally, the need to recognize the athlete's behavior as a complex system is exposed, where adaptation with time deficit is of vital importance. It is urged to overcome the vision of each approach in terms of finding convergent points, in an attempt to maximize the best of both perspectives.
\end{abstract}

e-ISSN: 2550-696X, p-ISSN: 2550-6978 ${ }^{\circ}$ Copyright 2019. The Author. SS Journals Published by Universidad Técnica de Manabí. This is an open-access article under the CC BY-SA 4.0 license (https://creativecommons.org/licenses/by-sa/4.0/) All rights reserved.

\section{Contents}

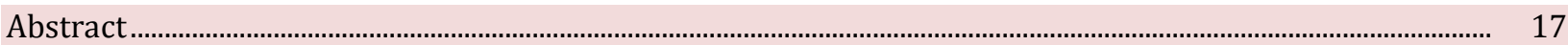

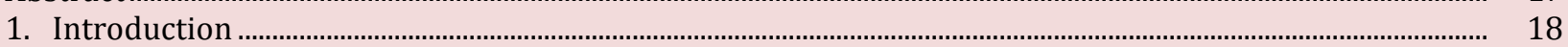

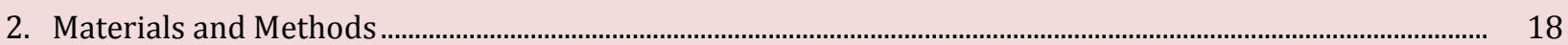

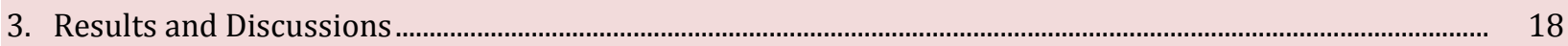

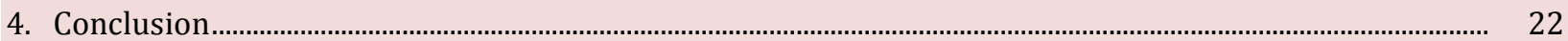

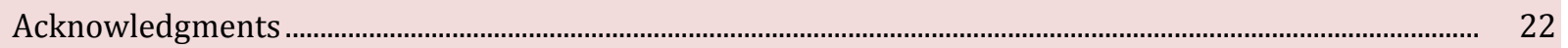

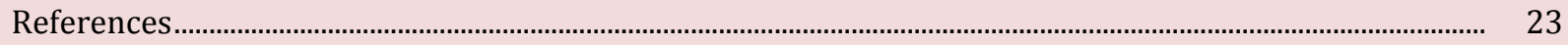

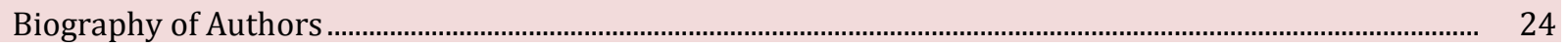

a Universidad de Oriente, Santiago de Cuba, Cuba

b Universidad de Camagüey, Camaguey, Cuba 


\section{Introduction}

Over the past decades, interest in gaining greater knowledge about the factors that influence the achievement of high athletic performance has It has been increased. This fact has caused that any professional related to the sports world, has seen the need to ask questions such as: What psychological variables determine that at a specific competitive moment, the performance is "good" or "bad"? How Can professionals associated with a sports team guarantee that the athlete obtains adequate performance in the competition?

To consider that an athlete has had a great performance, it is necessary, then, to mention a key skill in this regard: his decisive ability. Mediatized by both cognitive, emotional and situational processes that demand from the players a series of perceptual, decisive and executive abilities, which will be decisive in their sports performance.

Play well ... is to choose the most appropriate game option at all times and be able to carry it out efficiently and consciously throughout the game. Therefore the athlete's performance is determined by the ability to continue appropriate decision-making and mastery of technical skills, specific to the sport he practices (Gréhaigne et al., 1999)

It is clear that the study of the decision-making process in sport it is of vital importance, so a large number of specialists linked, for their work, to sports have conducted studies with the objective of understanding and explaining the decision process to improve sports performance. Studies have had different points of view in which sometimes converge and diverge ways to explain the phenomenon and how to train it with the best efficiency and in the shortest possible time.

Following this line, two fundamental ways of conceiving the process have emerged, one under the vision of cognitive psychology and another under an ecological approach. In each case, its initiators give great relevance to their particular conceptions, without taking into account that a global analysis of the process, in which indicators and concepts of both approaches are included in a systemic way, will provide a more complete vision of the object of study as well as the most successful way to train it.

The foregoing led us to consider as an objective of this article to present and clarify some ideas about the decision making in sport addressed by both paradigms, making reference, from a critical point of view, both to their convergences and to their theoretical divergences. A critical assessment was made on their object of study, the theories on which they are based, as well as the fundamental indicators and concepts they handle, based on the study carried out by García et al., (2011).

\section{Materials and Methods}

Theoretical methods such as the analytical-synthetic method were used during the theoretical systematization process of the analysis categories that underpin the study as well as in the determination of its essences and relationships. The inductive-deductive method was also used for a better understanding of the relationships that exist between the general and the particular object of study.

\section{Results and Discussions}

In the study of decision making in sports, as a cognitive process, two paradigms arise that stand out for their theories and methodological contributions of how to train this cognition in athletes, substantially improving their sports performance and performance in competitions

Researchers in sports psychology have dedicated extensive work to the study of decision making in sports because of its implications and its direct influence on the performance of athletes. There have been many investigations that address this issue, directing their interest to several aspects that make it up, some have preponderate the role of the cognitive processes involved, others have set their sights on emotional or emotional phenomena and only a few years ago it has emerged another edge that has its foundations, ecological aspects. 
In a first approach to these conceptions of decision making, it would impress great differences and different points of view of the same issue without keeping any relationship, that is, on the one hand the mental or internal processes (cognition and emotion) and external processes (situation). However, once studied the different theories that support these paradigms as well as the concepts and categories used to explain decision making. It is impossible to ignore the coincidences that arise between the two, if not in terms, if from a functional point of view and mediated by theoretical foundations of psychology that relate the individual directly to the surrounding context. You cannot theorize about psychological processes, without taking into account basic principles of science such as the relationship of the cognitive and the affective and the relationship with the environment as a source of information, learning and transformation.

Based on the panoramic study of the theories and research methods around decision-making in tennis, common aspects of both approaches are related.

\section{Objective pursued}

Explain decision making. The ecological model tries to explain it from unifying concepts of information and continuous dynamics, based on natural laws and the cognitive model will determine which processes are the most determining ones from the study of the information, cognitive strategies of the memory and anticipation processes, that is, visual-temporal and anemic parameters.

At first glance, it can be seen that both are based on the information-medium relationship, giving importance to the recognition, by the perceptual apparatus, of valuable information in a given space and time, which will be immediately stored in memory in the form of learning, creating a continuous dynamic between the medium and the individual collecting information.

\section{Theories of the approach}

The cognitive paradigm states that the decisive act occurs prior to the action and is carried out based on a previous perceptual process, depending largely on internal mental representations and the cognitive processes that mediate between the interpretation of a stimulus and the choice of an action On the other hand, the ecological paradigm supports its bases in the Theory of Direct Perception (Gibson, 1996, 1979 referred to García et al., 2011), where perception is specific to the environment in such a way that the perception relationship -action, is raised without mental mediators and decision making is a direct and emergent process (Araujo, 2006 referred to García et al., 2011).

Here again, the perceptual processing of the medium is mentioned and mentioned, as a catalyst for an action and vice versa, without the mediation of mental processes. However,

The speed of mental phenomena can give them a false impression of simplicity, in this case, perception occurs in "real time" in a seemingly simple and instantaneous way. But the efficiency and relative automatism of our perception does not imply in any way simplicity. The cognitive system, of which the perception-action relationship is part, is interactive, so there is a functional interdependence of all its components: attention, memory, thought, etc. (De Vega, 1994).

It is evident, then, that starting from the absence of mental processes is a bit naive since the information processing and its subsequent response are part of a complex and dynamic system.

\section{Concepts and Indicators}

The ecological paradigm operates with terms such as invariants being these properties of the visual system that remain constant during the changes produced by the subject or the environment (Gibson, 1979 referred to García et al., 2011), and the affordances that are nothing more than the possibilities of action offered by the environment, and these possibilities of action are perceived directly based on environmental data (Araujo, 2005; Araujo et al., 2006 referred to García et al., 2011).

In this same way, the cognitive approach uses terms that have common points of view with those described above, in a similar scenario. The need is then, in

Caurel, A. C., \& Sánchez, J. I. R. (2019). Critical assessment of paradigms in the study of decision making on sport. International Journal of Health Sciences, 3(3), 17-24. https://doi.org/10.29332/ijhs.v3n3.345 
knowing relevant informative indices in each task, and through a correct reading of the visual stimuli can produce a rapid decision making, an effective selection of the response and a more precise response that is, a greater efficiency of information processing stages (Luis, 2008).

This "correct reading" allows to make more effective the time available to the athlete to analyze the context. Together, perception is the interpretation of information quickly, so that the athlete has enough time to plan, initiate and execute a stroke successfully (Williams et al., 2004 referred to García et al., 2011). Likewise, once perceived patterns are related to the anticipatory skills that athletes must train, being conditioned by processes such as selective attention. The attention is in charge of eliminating or reducing redundant information clues or to react to a hit or predict a trajectory (Goulet et al., 1989; Singer et al., 1996 referred to García et al., (2011), as well as those important elements of the environment.

On the basis of dynamic principles, as defined by the ecological paradigm, the study of the decision process is sustained; these principles are:

time, defining it as the explanation of behaviors through time series and totality, understands that all aspects of a system are modified simultaneously and passed from a different state to another and finally the phase that does not it is more than the variations of the system within limits in a cycle (Araujo et al., 2006 referred to García et al., 2011).

Within the cognitive vision, allusion is also made to the study of temporal parameters, the was recognized

reaction time as a variable that determines the preparation of the movement and that would include the act of deciding, differentiating two processes: on the one hand selection of stimuli and on the other the selection of response, this selection depending on the response of the stimuli perceived previously (García, et al., 2011).

The ecological paradigm raises decision-making as a process of perception-action, describing how the information available in the environment can guide the actions of the subjects directly, without mediating internal mental processes. In this sense, a cognitive process is forgotten, memory, which is responsible for storing information in the form of learning. Current and past events will serve to plan future actions and predict game situations. This stored knowledge will condition decision making, so that the greater and more varied this knowledge, the better the anticipation and decision making of athletes.

In relation to the functioning of this knowledge and these internal processes in sport, it is proposed that

there are specific adaptations and structures that are stored in long-term memory, so that when deciding on a real game situation, the expert athlete, decides best due to two specialized adaptations of long-term memory: profiles of action plans, which consist of rules stored in long-term memory, which are used to match current conditions of the environment with motor actions and profiles of current events that are conceptualized as tactical scripts that guide the construction and constant modification of important concepts to take into account during the actions (McPherson, 1999 referred to García et al., 2011).

In contrast to cognitive psychology, three perspectives are exposed for mobile interception tasks:

the model-based control defining it as visual clues about the current position of the subject and the movement of the object that are combined with the knowledge of the dynamics of the environment to make spatial and temporal predictions of the point of interception; the information-based control, which explains how the information that is continuously available in the optical flow guides the athlete to the point of interception without the need to predict through internal models and a third perspective, conditioned by the individual abilities of the athletes and the perspective of affordances-based control and outlines that there is a restriction produced by the limitations of the actions that athletes are capable of performing, this perspective highlights the differentiation between possible and impossible actions (Fajen, 2007). 
It is important to highlight the importance of:

\begin{abstract}
affrodances in the decision-making process, together with other important aspects such as the knowledge of one's own limits, the learning of one's own capacities for action and the way to recalibrate them, since they will have a direct relationship with the taking of Athlete decisions (Fajen, 2007; Fajen et al ., 2009; Widana et al., 2018).
\end{abstract}

It is impossible not to find theoretical similarities in both paradigms, there are different works that have mentioned these same aspects, based on considering that knowledge stored in the form of scenarios, that is, indicators of conditions-action, objectives to be achieved and effects to produce (...) allows the athlete to understand the relationships between the different elements of the game situation (Iglesias et al., 2002; Llobet, 2005; Menéndez et al., 2019; Peter, 2015; Astra \& Artanayasa, 2017).

It is visible that even when different concepts are defined, the concepts and indicators they use, the approaches refer to the same phenomena. In this case, cognitive psychology studies a process, thinking, and more linked to sport tactical or operational thinking, which will allow to act correctly by guiding the mental processes of action. This thought delimits the selection of significant indexes on which to focus attention, thus largely determining the quality of decisions and the real possibilities of action, allowing the athlete to develop appropriate anticipation strategies. In addition, mention is made of the existence of an apprenticeship, an experiential knowledge previously acquired, with information from both the adversary, the game situation and the athlete himself. From the cognitive point of view the last phase, so to speak, of the decision-making process, constitutes a feedback or evaluation of the decision taken, where the subject assesses whether it was correct or not and that experience stores it as learning in memory creating a dynamic cycle at the moment that it returns to perceive the relevant information in another game situation.

Finally, those who defend the ecological conception, suggest that decision making will emerge from an active process of exploration and selection of relevant information to regulate actions that allow achieving a goal (Araujo et al., 2004 referred to García et al., 2011). While the cognitive approach presents the decision process as a complex process. It is the product of information processing in which the athlete uses cognitive strategies based on working memory and knowledge structure (Bar-Eli \& Raab, 2006; Sarkar \& Kumar, 2016) also point out that it is derived from anticipatory processes, observed in the figure 1.

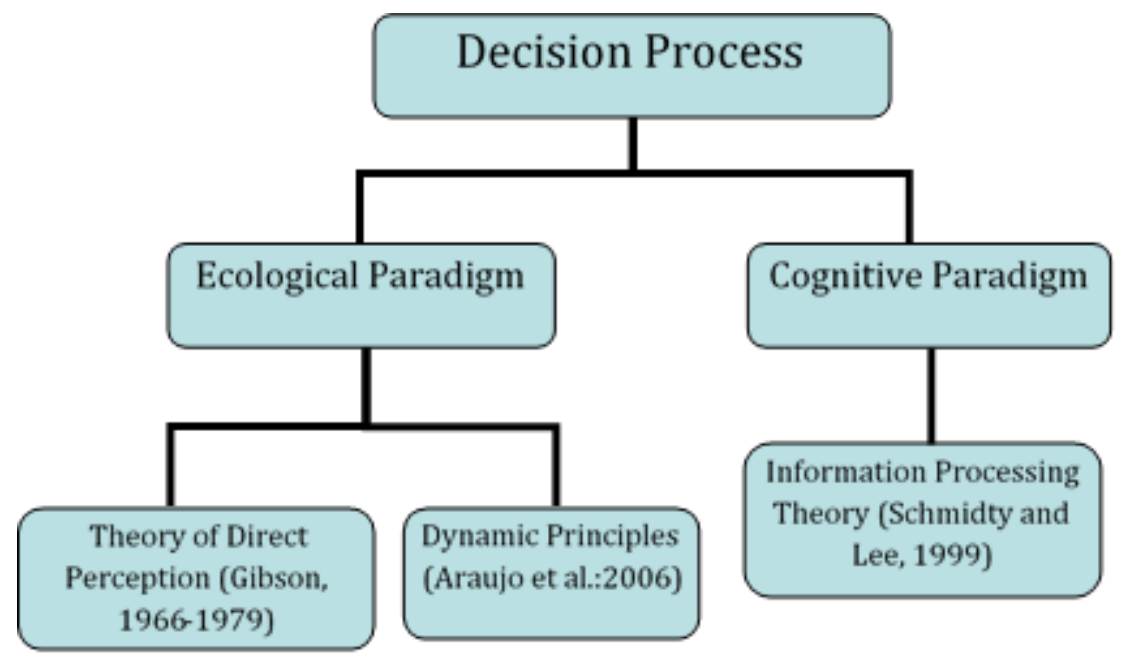

Figure 1. Anticipatory processes

Caurel, A. C., \& Sánchez, J. I. R. (2019). Critical assessment of paradigms in the study of decision making on sport. International Journal of Health Sciences, 3(3), 17-24. https://doi.org/10.29332/ijhs.v3n3.345 


\section{Conclusion}

The scientific study of the human mind is as difficult a task as it is interesting. Given that mental phenomena are "inaccessible" to external observation, theories that attempt to explain their processes must be based on data extracted from introspective observation or in other cases from behavioral data from which to draw inferences. In addition, mental processes are very fast, causing an erroneous impression of simplicity, constituting exactly the opposite, it is a complex and interactive system and there is a functional dependence on all components. This reality puts the researcher in a difficult position, since science has the tendency to fragment complex processes into parts, for a "better" study.

After conducting a brief analysis of the decision process, from the ecological perspective and from the perspective of cognitive psychology as a summary, some relevant questions are raised in the study of this process for sports performance.

Recognize the training and competition process, as well as the athlete's behavior as a complex system, where learning arises from situations in which it should adapt as well as possible and in less time, requires specialists and scholars of the subject go beyond one perspective or another and find that there are points of convergence rather than divergence. Being able to overcome the vision that each approach has of the same phenomenon in terms of understanding human thought as the base substrate of all these psychological phenomena and that allows planning and deciding in any real situation faced by the athlete.

It is understood that cognitivism exposes important phenomena within the decision-making process of the athlete, but sometimes tends to offer a static and uniform vision. Limit the explanation of what really happens in changing and unforeseen contexts. The ecological paradigm, on the other hand, seems to "fill" that void, basing its arguments on real game situations, legitimizing the study and training of the process in real situations although, it loses sight of the basic mental processes that provide support to the subject-medium interaction.

Both paradigms are then recognized as effective ways of approaching decision making and training. Taking into account the studies carried out under the influence of the theories that support them, which have also contributed important results and that describe the reality of the situations that the athlete faces both in training and in competition. However, the limitations of both paradigms require alternative theories that combine the contributions made into a single theoretical system.

Starting from the indissoluble union of the cognitive and situational processes of the two approaches although their authors strive to separate themselves, from the point of view of the use of different terms and concepts; the author values that the exposed paradigms are not at all incompatible, so that this study constitutes an attempt to make the most of both approaches.

Acknowledgments

We thank the editor of IJHS for their valuable time, support and advice. 
References

Araujo, D., Davids, K., \& Hristovski, R. (2006). The ecological dynamics of decision making in sport. Psychology of sport and exercise, 7(6), 653-676. https://doi.org/10.1016/j.psychsport.2006.07.002

Araújo, M. B., \& Rahbek, C. (2006). How does climate change affect biodiversity?. Science, 313(5792), 13961397. https://doi.org/10.1126/science.1131758

Araújo, M. G., \& Lindhe, J. (2005). Dimensional ridge alterations following tooth extraction. An experimental study in the dog.Journal of clinical periodontology, 32(2), 212-218. https://doi.org/10.1111/j.1600051X.2005.00642.X

Araujo, R., Rodrigues, A. G., \& Pina-Vaz, C. (2004). A fast, practical and reproducible procedure for the standardization of the cell density of an Aspergillus suspension. Journal of medical microbiology, 53(8), 783-786. https://doi.org/10.1099/jmm.0.05425-0

Astra, I. K. B., \& Artanayasa, I. W. (2017). Developing instructional material for sepak takraw playing technique course completed with smart audiovisual to improve competencies of the students of sport \& health education department ganesha university of education. International Research Journal of Engineering, IT \& Scientific Research, 3(4), 66-76.

Bar-Eli, M., \& Raab, M. (2006). Judgment and decision making in sport and exercise: Rediscovery and new visions. https://psycnet.apa.org/doi/10.1016/j.psychsport.2006.07.003

De Vega, M. (1994). Characters and their perspectives in narratives describing spatial environments. Psychological Research, 56(2), 116-126. https://doi.org/10.1007/BF00419719

Fajen, B. R. (2007). Affordance-based control of visually guided action. Ecological Psychology, 19(4), 383-410. https://doi.org/10.1080/10407410701557877

Fajen, B. R., Riley, M. A., \& Turvey, M. T. (2009). Information, affordances, and the control of action in sport. international Journal of sport psychology, 40(1), 79.

García-Pérez, R., Rebollo, M. Á., Vega, L., Barragán-Sánchez, R., Buzón, O., \& Piedra, J. (2011). El patriarcado no es transparente: competencias del profesorado para reconocer desigualdad. Cultura y Educación, 23(3), 385-397. https://doi.org/10.1174/113564011797330298

Gibson, B. S. (1996). The masking account of attentional capture: A reply to Yantis and Jonides (1996). https://psycnet.apa.org/doi/10.1037/0096-1523.22.6.1514

Gibson, C. G. (1979). Singular points of smooth mappings (Vol. 25). Pitman publishing.

Goulet, C., Bard, C., \& Fleury, M. (1989). Expertise differences in preparing to return a tennis serve: A visual information processing approach.Journal of sport and Exercise Psychology, 11(4), 382-398. https://doi.org/10.1123/jsep.11.4.382

Gréhaigne, J. F., Godbout, P., \& Bouthier, D. (1999). The foundations of tactics and strategy in team sports. Journal of teaching in physical education, 18(2), 159-174. https://doi.org/10.1123/jtpe.18.2.159

Iglesias, M. A., Ye, J. M., Frangioudakis, G., Saha, A. K., Tomas, E., Ruderman, N. B., ... \& Kraegen, E. W. (2002). AICAR administration causes an apparent enhancement of muscle and liver insulin action in insulinresistant high-fat-fed rats. Diabetes, 51(10), 2886-2894. https://doi.org/10.2337/diabetes.51.10.2886

Llobet, V. (2005). La promoción de resiliencia con niños y adolescentes: entre la vulnerabilidad y la exclusión: Herramientas para la transformación. Noveduc Libros.

Luis, V. (2008). Influence of perceptual training, based on anticipation, on visual behavior and reaction response applied to tennis. (PhD thesis). University of Extremadura, Cáceres.

McPherson, A. (1999). Crystallization of biological macromolecules.

Menéndez, I. Y. C., Napa, M. A. C., Moreira, M. L. M., \& Zambrano, G. G. V. (2019). The importance of formative assessment in the learning teaching process. International Journal of Social Sciences and Humanities, 3(2), 238-249. https://doi.org/10.29332/ijssh.v3n2.322

Peter, V. F. (2015). Relationship among culture, education and sports. International Research Journal of Management, IT and Social Sciences, 2(11), 38-42.

Sarkar, S., \& Kumar, K. M. (2016). A critical assessment of the swarnajayanti gram swarojagar yojana in india. International Research Journal of Management, IT and Social Sciences, 3(3), 95-100.

Singer, L. T., Davillier, M., Bruening, P., Hawkins, S., \& Yamashita, T. S. (1996). Social support, psychological distress, and parenting strains in mothers of very low birthweight infants. Family Relations, 45(3), 343. https://dx.doi.org/10.2307\%2F585507

Caurel, A. C., \& Sánchez, J. I. R. (2019). Critical assessment of paradigms in the study of decision making on sport. International Journal of Health Sciences, 3(3), 17-24. https://doi.org/10.29332/ijhs.v3n3.345 
Widana, I. W., Parwata, I. M. Y., Parmithi, N. N., Jayantika, I. G. A. T., Sukendra, K., \& Sumandya, I. W. (2018). Higher order thinking skills assessment towards critical thinking on mathematics lesson. International Journal of Social Sciences and Humanities, 2(1), 24-32. https://doi.org/10.29332/ijssh.v2n1.74

Williams, T. M., \& Lisanti, M. P. (2004). The Caveolin genes: from cell biology to medicine. Annals of medicine, 36(8), 584-595. https://doi.org/10.1080/07853890410018899

\section{Biography of Authors}

\begin{tabular}{|c|c|}
\hline & $\begin{array}{l}\text { Degree in Psychology, with nine years of experience, six of them in Sports } \\
\text { Psychology. He works at the Provincial Center of Sports Medicine in Santiago de } \\
\text { Cuba in the care of high performance athletes and is a member of the Scientific } \\
\text { Council of the same. It follows the line of research "Development of the decision } \\
\text { process in high performance sport" within the Macroproject of the Department of } \\
\text { Psychology. He has participated in national and international events related to } \\
\text { different branches of Psychology. } \\
\text { Email: amaya.castillo@nauta.cu }\end{array}$ \\
\hline & $\begin{array}{l}\text { Professor, Dr. C of Physical Culture, has twelve years of experience in Higher } \\
\text { Education. Vice Dean of Research and Postgraduate of the Faculty of Physical } \\
\text { Culture of the University of Camagüey "Ignacio Agramonte Loynaz". Professor of } \\
\text { Theory and Methodology of Sports Training. Member of the academic plant of the } \\
\text { Master of Sports Psychology, Sports Pedagogy, Teaching of Contemporary Physical } \\
\text { Education, coordinator of the Master's Degree in Sports Training and the } \\
\text { curricular PhD of Physical Culture. } \\
\text { Email: jose.ruiz61182@gmail.com } \\
\text { Jose.ruiz61182@reduc.edu.cu }\end{array}$ \\
\hline
\end{tabular}

